\title{
Care of Women with Chronic Inflammatory Bowel Disease (Chronic IBD) During Pregnancy
}

Recommendations of the Obstetrics and Prenatal Medicine Working Group

of the DGGG

\section{Betreuung von Frauen mit chronisch entzündlichen Darmerkrankungen (CED) in der Schwangerschaft}

\author{
Empfehlungen der Arbeitsgemeinschaft für Geburtshilfe und Pränatalmedizin \\ in der DGGG
}

\section{(이 (i) (요 $\ominus$}

Authors

Markus Schmidt ${ }^{1}$, Maritta Kühnert ${ }^{2}$, Bettina Kuschel ${ }^{3}$, Sven Kehl ${ }^{4}$, Ute Margaretha Schäfer-Graf ${ }^{5}$

Affiliations

1 Klinik für Frauenheilkunde und Geburtshilfe, Sanakliniken Duisburg, Duisburg, Germany

2 Klinik für Frauenheilkunde und Geburtshilfe, Universitätsklinikum Marburg, Marburg, Germany

3 Klinik und Poliklinik für Frauenheilkunde, Klinikum rechts der Isar, Technische Universität München, München, Germany

4 Frauenklinik, Universitätsklinikum Erlangen, Erlangen, Germany

5 Berliner Diabeteszentrum für Schwangere, St. Joseph Krankenhaus Berlin, Berlin, Germany

Key words chronic inflammatory bowel disease, Crohn's disease, ulcerative colitis, pregnancy

Schlüsselwörter

chronisch entzündliche Darmerkrankung, Morbus Crohn, Colitis ulcerosa, Schwangerschaft

received 28.2.2021

accepted after revision $\quad$ 10.3.2021

Bibliography

Geburtsh Frauenheilk 2021; 81: 1348-1353

DOI 10.1055/a-1429-2742

ISSN 0016-5751

(C) 2021. The Author(s).

This is an open access article published by Thieme under the terms of the Creative Commons Attribution-NonDerivative-NonCommercial-License, permitting copying and reproduction so long as the original work is given appropriate credit. Contents may not be used for commercial purposes, or adapted, remixed, transformed or built upon. (https://creativecommons.org/licenses/by-nc-nd/4.0/)

Georg Thieme Verlag KG, Rüdigerstraße 14,

70469 Stuttgart, Germany
Correspondence

Prof. Dr. Markus Schmidt

Sana Kliniken Duisburg

Zu den Rehwiesen 9, 47055 Duisburg, Germany

Markus.schmidt@sana.de

丹 Deutsche Version unter:

https://doi.org/10.1055/a-1429-2742

\section{ABSTRACT}

The incidence of chronic inflammatory bowel disease (chronic IBD) in persons of reproductive age is high. Chronic IBD does not typically lead to impaired fertility. Nevertheless, the percentage of women suffering from chronic IBD who have children is lower than that of the general population, due to selfimposed childlessness. Providing women with open, unbiased information and, if necessary, helping them to overcome baseless fears should therefore be an essential part of preconception counseling. With the exception of methotrexate, most standard drugs can and should be continued during pregnancy. If the pregnancy occurs during an inactive phase of disease, the rate of complications in pregnancy should, in principle, not be higher than normal. Nevertheless, pregnant women with chronic IBD are classed as high-risk pregnancies. Organ screening in accordance with DEGUM II criteria should be carried out in every case, and women must be monitored for the potential development of placental insufficiency. Any flare-ups which occur during pregnancy should be treated in full. Vaginal delivery can be considered if there is no perianal manifestation of disease; however, the individual risk must be carefully weighed up. 


\section{ZUSAMMENFASSUNG}

Chronisch entzündliche Darmerkrankungen (CED) weisen eine hohe Inzidenz im reproduktionsfähigen Alter auf. Eine CED führt typischerweise nicht zu einer beeinträchtigten Fertilität, dennoch ist die Rate an Frauen mit Kindern aufgrund einer selbstauferlegten Kinderlosigkeit geringer als in der Gesamtpopulation. Ergebnisoffen zu informieren und ggfs. unbegründete Ängste abzubauen, sollte daher ein wesentlicher Bestandteil der präkonzeptionellen Beratung sein. Die gängigen Medikamente mit Ausnahme von Methotrexat können und sollen in der Schwangerschaft fortgeführt werden. Tritt die Schwangerschaft in einer inaktiven Krankheitsphase ein, so ist prinzipiell nicht mit einer erhöhten Komplikationsrate in der Schwangerschaft zu rechnen. Dennoch gelten Frauen mit CED als Risikoschwangere. Es sollte in jedem Fall ein Organscreening nach DEGUM-II-Kriterien erfolgen sowie auf die evtl. Entwicklung einer Plazentainsuffizienz geachtet werden. Ein möglicher Schub in der Schwangerschaft sollte konsequent therapiert werden. Beim Fehlen einer perianalen Manifestation kann eine vaginale Entbindung angestrebt werden, dennoch ist eine individuelle Risikoabwägung erforderlich.

\section{Forms of Chronic Inflammatory Bowel Disease}

\section{AGG STATEMENT}

The two most important forms of chronic inflammatory bowel diseases in pregnancy are Crohn's disease and ulcerative colitis.

Chronic inflammatory bowel disease (chronic IBD) is the term used to describe immune-mediated chronic inflammation of the bowel. The two most important forms of chronic IBD are Crohn's disease and ulcerative colitis.

Crohn's disease is typically a non-continuous inflammation extending from the terminal ileum to a segmental colitis, which often spares the rectum. Many patients do develop perianal changes with fistula formation. Affected persons suffer from abdominal pain; abdominal resistance develops and stenosis of the small intestine is common. The incidence of disease is approximately 6.6/100000; the mean age at onset of disease is 33 years. The definitive diagnosis is obtained using sonographic imaging and an ileocolonoscopy to provide evidence of discontinuous inflammation together with histological confirmation of granulomas [1].

Ulcerative colitis typically is a continuous inflammation emanating from the rectum. Affected persons may pass blood or mucus in their stools, although pain only occurs intermittently. Stenosis or fistula formation does not occur. The incidence is approximately 3-3.9/100 000. The highest age-specific incidence occurs between the ages of 16 and 25 years. The diagnosis of ulcerative colitis is based on the patient's history, ultrasound examinations, and endoscopic findings [2].

There are some transitional forms between the two types of chronic IBD. The following recommendations were agreed by the AGG. The recommendations are based on a search of the literature, and they aim to provide assistance to treating physicians during preconception counseling and when caring for affected patients.

\section{Methods}

A literature search of the PubMed database for the period from 1995 to January 2021 was carried out, using the search terms "chronic inflammatory bowel disease and pregnancy". Randomized clinical studies on this issue are lacking. Almost 200 publications were found during the literature search. The articles considered to be most relevant for the care of pregnant patients with chronic IBD were reviewed. They were taken as the basis for recommendations on the treatment of women with chronic inflammatory bowel disease in pregnancy, and voted on by the "Maternal Diseases" section of the Obstetrics and Prenatal Medicine Working Group of the DGGG (AGG).

\section{Preconception Counseling}

\section{AGG RECOMMENDATION}

Women with chronic inflammatory bowel disease should be offered preconception counseling.

\section{AGG RECOMMENDATION}

Clinical remission of disease should be aimed for prior to conception, as disease activity at the time of conception is correlated with an increased risk of premature birth and placental insufficiency.

\section{AGG RECOMMENDATION}

With the exception of methotrexate, medication to maintain remission or deal with a flare-up should, where indicated, be continued even if the woman wishes to have a child.

The fertility of women with Crohn's disease is not or only slightly lower [3]. Reduced fertility has only been reported for patients with active ulcerative colitis or who have undergone placement of an ileoanal pouch (IAP) [4]. Nevertheless, the percentage of affected persons who have children is lower than in the overall pop- 
ulation. This voluntary childlessness has been reported for both women and men with chronic IBD [4]. Reported causes include fear of heritability, the risk of fetal malformations, and worries about the teratogenicity of the medication [5].

Although women with chronic IBD often receive long-term medical care, there appears to be a lot of uncertainty around family planning. These women are in urgent need of counseling and would particularly benefit from preconception counseling [6].

Discussions during counseling should include the discussion on how chronic IBD can affect the course of pregnancy and the impact pregnancy may have on chronic IBD.

Stable disease with the disease in remission does not affect the course of pregnancy, and pregnancy has no negative impact on disease activity. A European cohort study showed that the flareup rate among women who were stable prior to conception is comparable with the rate reported for non-pregnant women. However, if conception occurs during an active disease phase, then $2 / 3$ of women had increased flare-ups during the subsequent course of pregnancy and an higher risk of worsening disease after pregnancy [7].

Active disease during conception was also found to be correlated with an increased risk of miscarriage, premature birth, and a higher incidence of growth-restricted fetuses [8,9].

A recent meta-analysis [10] showed a 2.42 times higher risk of premature birth (95\% Cl: 1.81-8.02), a 1.48 times higher risk of SGA (95\% Cl: 1.19-1.85), a 1.87 times higher risk of miscarriage (95\% Cl: 1.17-3.0), and a 2.27 times higher risk of intrauterine fetal death (95\% Cl: 1.03-5.04) in women who had active disease at the time of conception compared to women with inactive disease at conception.

The majority of women with chronic IBD take long-term medication which needs to be reviewed before becoming pregnant.

According to the recommendations of the European Crohn's and Colitis Organisation (ECCO) and the AWMF guideline on Crohn's disease $[1,11]$, women can continue to take their usual medication with the exception of methotrexate.

According to information from Embryotox, 5-ASA drugs, particularly mesalazine and sulfasalazine, have been investigated in detail and are considered to be generally very well tolerated. Glucocorticoids are permissible at all stages of pregnancy. Possible effects on the fetus depend on the glucocorticoid, the dosage, the duration of treatment, and the period of pregnancy. As local applications such as budenoside are not absorbed very well, they are considered harmless. If treatment consists of systemic application of a drug, it is important to bear in mind that fluorinated corticosteroids such as dexamethasone and betamethasone cross the placental barrier, while non-fluorinated preparations such as prednisone and prednisolone are largely enzymatically inactivated in the placenta. Systemic long-term medication with corticoids should be avoided where possible. In the rare cases requiring higher dose treatment over many weeks, fetal growth should be monitored by ultrasound. If treatment is continued up until the birth, it is important to be aware of the possibility of adrenal insufficiency in the neonate and to treat the infant accordingly. The mother may also develop relative adrenal insufficiency when giving birth, and steroid treatment should be adjusted peripartum if necessary. When planning the birth, it is important to already con-
- Table 1 Overview of the most common medications used to treat chronic IBD and their safety during pregnancy.

\begin{tabular}{|l|l|l|}
\hline Safe & Probably safe & Contraindicated \\
\hline Oral 5-aminosalicylates & Infliximab & Methotrexate \\
\hline Topical 5-aminosalicylates & Adalimumab & Thalidomide \\
\hline Sulfasalazine/mesalazine & Certolizumab & $\begin{array}{l}\text { 6-Thioguanine } \\
\text { (no data) }\end{array}$ \\
\hline Azathioprine & Cyclosporine & \\
\hline 6-Mercaptopurine & Tacrolimus & \\
\hline & Budenoside & \\
\hline & Metronidazole & \\
\hline & Ciprofloxacin & \\
\hline
\end{tabular}

sider how to adjust the steroid dosages in stress situations for any pregnant woman receiving long-term steroid therapy and to set up a substitution plan.

Azathioprine, followed by cyclosporine, is the most studied immunomodulator. TNF- $\alpha$ inhibitors are also acceptable if their use is imperative. However, the administration of TNF- $\alpha$ inhibitors in the second half of pregnancy should be limited to selected cases and must be justified. The antibiotic drugs metronidazole and ciprofloxacin can be used in pregnancy [12].

- Table 1 lists the most common drugs used to treat chronic IBD and their safety levels in pregnancy (modified from [13]).

Data on the monoclonal $\lg \mathrm{G} 1$ antibodies vedolizumab and ustekinumab in pregnancy is limited. Both drugs should therefore only be used during pregnancy after carefully weighing up the benefits and disadvantages in each individual case and after other treatment options have failed $[12,14]$.

\section{Care During Pregnancy}

\section{AGG RECOMMENDATION}

Pregnant women with chronic inflammatory bowel disease should be cared for by a gastroenterologist who is supported an interdisciplinary team.

\section{AGG RECOMIMENDATION}

With the exception of methotrexate, treatment to maintain disease remission should not be discontinued in pregnancy.

\section{AGG RECOMMENDATION}

The diagnostic work-up should consist of carefully differentiated, sonography-based detailed examinations in accordance with DEGUM II criteria. 


\section{AGG RECOMMENDATION}

Regular sonographic controls should be carried out

(at least every 4 weeks) to confirm fetal growth.

\section{AGG RECOMMENDATION}

Flare-ups of chronic inflammatory bowel disease in pregnancy must be treated.

\section{AGG RECOMMENDATION}

From week $40+0$ of gestation, the pregnant woman should be informed about the option of inducing labor.

The overall data on pregnancy risks is inconsistent. Some studies have reported a higher risk of premature birth in women with chronic IBD, particularly women who had active disease during pregnancy $[15,16]$. In a meta-analysis carried out in 2007, the risk of premature birth for women with chronic IBD was 1.87 times higher (95\% Cl: 1.52-2.31, p<0.001) [16]. A more recent metaanalysis came to a similar conclusion, reporting a 1.85 times higher risk of premature birth [18]. As the causes of premature birth (e.g., preterm labor, premature rupture of membranes or iatrogenic cause due to fetal growth restriction) were not differentiated in the studies, is it not possible to make any generalized statements on the etiology of these premature births.

The meta-analysis by O'Toole et al. found a 1.36 times higher risk of SGA (small for gestational age) fetuses ( $95 \% \mathrm{Cl}$ : 1.16-1.60), while the meta-analysis by Cornish even reported a 2 times higher risk of giving birth to an infant with a birth weight of $<2500 \mathrm{~g}$. The analysis did not differentiate between fetal growth restriction (e.g., due to placental insufficiency) and constitutionally small fetuses with no pathological causes. The reason for the increased rate of smaller infants can therefore not be conclusively determined. In addition to the risk of placental insufficiency, the effects of anti-inflammatory drugs and the parent's constitution must also be weighed up.

The above-mentioned meta-analyses found an increased risk of malformations. The risk was calculated to be 1.3 and 2.3 times higher, although no serious malformations were reported. The meta-analysis by Cornish et al. only reported an increased risk of malformations for patients with ulcerative colitis. No increased risk was found for patients with Crohn's disease. The risk of intrauterine fetal death was marginally higher by a factor of 1.57 in the meta-analysis by Cornish et al.; this was not confirmed in the meta-analysis by O'Toole. However, both meta-analyses almost exclusively used only retrospective case series, meaning that the results must be interpreted with caution.

A prospective European study of 332 pregnant women with chronic IBD investigated the course of pregnancy in patients with chronic IBD compared to a matched control group [19]. According to this study, there was no difference in the rates of live births, miscarriages, intrauterine fetal deaths, premature births, SGA fe- tuses, and cesarean sections. A maternal age of $>35$ and smoking were risk factors for premature birth and associated with a higher rate of fetal malformations.

Patients should also be monitored for the development of gestational diabetes, as the incidence of gestational diabetes is higher in women with chronic IBD [20].

In summary, it is not possible to make a reliable statement about the course of pregnancy in women with chronic IBD, which is why any flare-ups in pregnancy must be treated. Pregnancies of women with chronic IBD are considered high-risk pregnancies. These women should be monitored by an interdisciplinary team who can advise the treating gastroenterologist. Organ screening in accordance with DEGUM II criteria should be carried out in every case, and particular attention should be paid over the course of the pregnancy to the possible development of fetal growth restriction. As the data on the risk of intrauterine fetal death is not clear, the pregnant woman should be informed about the option of having her labor induced at her calculated due date.

\section{Mode of Delivery}

\section{AGG RECOMMENDATION}

Pregnant women with ulcerative colitis and an ileoanal pouch should be advised to have a cesarean section.

\section{AGG RECOMMENDATION}

Pregnant women with active perianal Crohn's disease should be advised to have a cesarean section.

\section{AGG RECOMMENDATION}

Prophylactic episiotomy should not be carried out.

A recent retrospective study of 124 patients with chronic IBD found increased cesarean section rates, with $63.1 \%$ of women with ulcerative colitis and $40.7 \%$ of women with Crohn's disease having a cesarean section [21]. The highest cesarean section rates for women with Crohn's disease were found in women with active or inactive perianal disease. In the group of women with ulcerative colitis, the highest cesarean section rate was found in the group of women with an ileoanal pouch (IAP). The cesarean section rate in the meta-analysis by Cornish was 1.5 times higher for women with chronic IBD compared to the control group [17]. The differentiated analysis showed that the cesarean section rate was only significantly increased in the group of women with Crohn's disease, while the increase in women with ulcerative colitis was not significant. However, in the prospective study by Bortoli et al., the cesarean section rate was not higher in women with chronic IBD [19].

As large prospective studies are lacking, the question inevitably arises about the criteria that should be used by the physician 


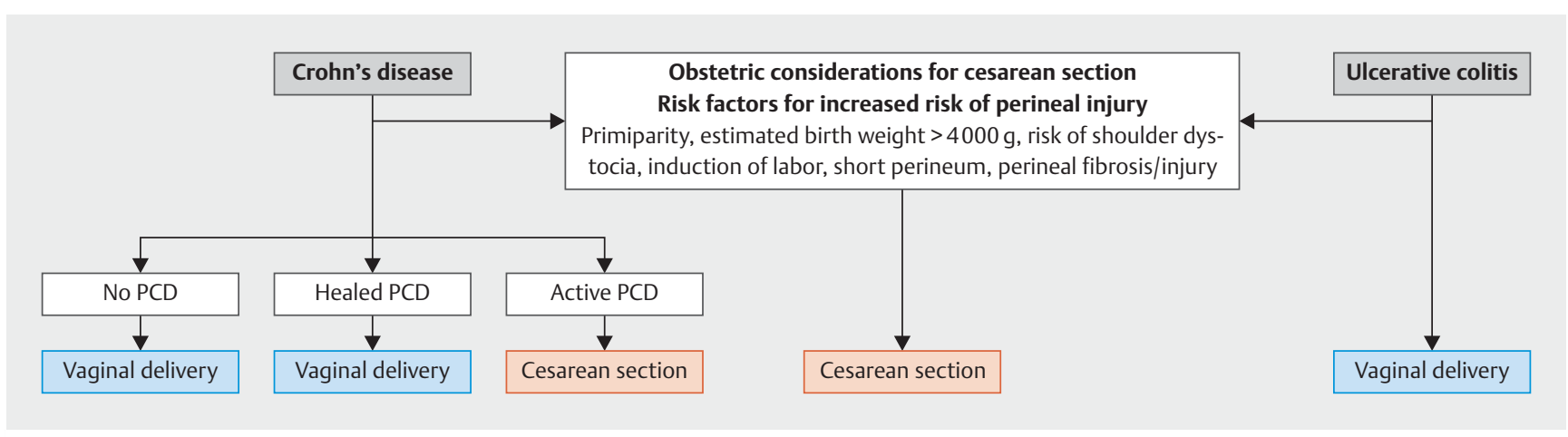

- Fig. 1 Algorithm to determine the mode of delivery for patients with chronic IBD and a prior history of ileoanal anastomosis $(P C D=$ perianal Crohn's disease) [22].

when considering the planned mode of delivery and discussing it with the expectant mother. In addition to the wishes of the mother, who typically will have a long history of disease, a number of different aspects need to be considered when determining the mode of delivery. Considerations which must be incorporated in the decision in every case include the type of disease, the disease activity, any prior abdominal surgery and the patient's obstetric history. Typically, patients are very worried about potential perianal injuries, wound healing disorders, fistula formation, pelvic floor injuries and possible subsequent incontinence [22].

The ECCO [18] recommends vaginal delivery in women with inactive or mild forms of disease and cesarean section for women with active perianal or rectal disease. In a systematic review, Foulon et al. were able to show that the overall cesarean section rate was higher for women with chronic IBD [24]. One of the reasons for this could be the fear of developing perianal disease and possibly incontinence after vaginal delivery.

However, it appears that worries about developing perianal manifestation of disease after vaginal delivery could be unfounded [24]. Even an episiotomy, vaginal-surgical delivery and birth injuries did not lead to a higher incidence of perianal manifestation in this group of patients. More episiotomies were carried out to prevent 3rd or 4th degree perineal tears. However, the benefit of carrying out a prophylactic episiotomy to avoid 3rd or 4th degree perineal tears is extremely dubious and prophylactic episiotomies should not be carried out [24]. As expected, the rate of cesarean sections in women with perianal manifestation of disease prepartum was significantly higher. In the group of women who aimed for vaginal delivery despite active perianal disease, there was a tendency for disease to get worse after vaginal delivery. The risk for women with healed perianal lesions should be carefully considered. Risks include parity, estimated fetal birth weight, perineal distance and consistency of the perineum.

Women with ulcerative colitis and an ileoanal pouch (IAP) represent a special group of women with IBD. One study reported an increased rate of sphincter defects with impairment of the pouch function, and these patients should be advised to have a cesarean section [26].
- Fig. 1 shows a potential algorithm which can be used to determine the appropriate mode of delivery for patients with no ileoanal pouch $[22,24]$.

\section{Postpartum Care}

\section{AGG RECOMMENDATION}

The medication prescribed to treat chronic inflammatory bowel disease should be continued during lactation.

\section{AGG RECOMMENDATION}

Use of mesalazine and corticosteroids can be continued during the period of lactation after carefully weighing up the indications.

The benefits of breastfeeding for mother and child are undisputed. Maternal worries about the safety of medication during lactation means that women often stop regularly taking their medication. According to some reports, $60 \%$ of women with Crohn's disease decide to stop taking their medication because of concerns that the drugs could harm their child if the infant is being breastfed [27].

Most medications are compatible with breastfeeding. Less than $1 \%$ of the maternal plasma dosage of corticoids, thiopurines or anti-TNF preparations is transferred and these medications should therefore be classed as harmless [28]. In every case, the issue should be discussed by interdisciplinary team.

\section{Conflict of Interest}

The authors declare that they have no conflict of interest. 


\section{References}

[1] Preiß JC, Bokemeyer B, Buhr HJ et al.; German Society of Gastroenterology. [Updated German clinical practice guideline on „Diagnosis and treatment of Crohn's disease“ 2014]. Z Gastroenterol 2014; 52: 1431-1484. doi:10.1055/s-0034-1385199

[2] Kucharzik T, Dignass AU, Atreya R et al.; Collaborators. Aktualisierte S3Leitlinie Colitis ulcerosa - Living Guideline. Z Gastroenterol 2020; 58: e241-e326. doi:10.1005/a-1296-3444

[3] Hudson M, Flett G, Sinclair TS et al. Fertility and pregnancy in inflammatory bowel disease. Int J Gynaecol Obstet 1997; 58: 229-237

[4] Vermeire S, Carbonnel F, Coulie P et al. Management of inflammatory bowel disease in pregnancy. J Crohns Colitis 2012; 6: 811-823

[5] Mountifield R, Bampton P, Prosser R et al. Fear and fertility in inflammatory bowel disease: a mismatch of perception and reality affects family planning decisions. Inflamm Bowel Dis 2009; 15: 720-725

[6] Schmidt M. Präkonzeptionelle Beratung. Frauenheilkunde up2date 2018; 12: 23-35

[7] Riis L, Vind I, Politi P et al. Does pregnancy change the disease course? A study in a European cohort of patients with inflammatory bowel disease. Am J Gastroenterol 2006; 101: 1539-1545

[8] Moser MA, Okun NB, Mayes DC et al. Crohn's disease, pregnancy, and birth weight. Am J Gastroenterol 2000; 95: 1021-1026

[9] Nørgård B, Hundborg HH, Jacobsen BA et al. Disease activity in pregnant women with Crohn's disease and birth outcomes: a regional Danish cohort study. Am J Gastroenterol 2007; 102: 1947-1954

[10] Kim MA, Kim YH, Chun J et al. The influence of disease activity on pregnancy outcomes in women with inflammatory bowel disease: A systematic review and meta-analysis. J Crohns Colitis 2020: jjaa225. doi:10.1093/ecco-jcc/jjaa225

[11] Magro F, Gionchetti P, Eliakim R et al.; European Crohn's and Colitis Organisation [ECCO]. Third European Evidence-based Consensus on Diagnosis and Management of Ulcerative Colitis. Part 1: Definitions, Diagnosis, Extra-intestinal Manifestations, Pregnancy, Cancer Surveillance, Surgery, and Ileo-anal Pouch Disorders. J Crohns Colitis 2017; 11: 649-670

[12] Embryotox. Pharmakovigilanz- und Beratungszentrum für Embryonaltoxikologie; Charité-Universitätsmedizin Berlin, Campus Virchow-Klinikum, Augustenburger Platz 1, 13353 Berlin. Accessed March 06, 2021 at: www.embryotox.de

[13] van der Woude C], Kolacek S, Dotan I et al.; for the European Crohn's Colitis Organisation (ECCO). European evidenced-based consensus on reproduction in inflammatory bowel disease. J Crohns Colitis 2010; 4: 493-510
[14] Laube R, Paramsothy S, Leong RW. Use of medications during pregnancy and breastfeeding for Crohn's disease and ulcerative colitis. Expert Opin Drug Saf 2021. doi:10.1080/14740338.2021.1873948

[15] Bush MC, Patel S, Lapinski RH et al. Perinatal outcomes in inflammatory bowel disease. J Matern Fetal Neonatal Med 2004; 15: 237-241

[16] Reddy D, Murphy S], Kane SV et al. Relapses of inflammatory bowel disease during pregnancy: in-hospital management and birth outcomes. Am J Gastroenterol 2008; 103: 1203-1209

[17] Cornish J, Tan E, Teare J et al. A meta-analysis on the influence of inflammatory bowel disease on pregnancy. Gut 2007; 56: 830-837

[18] O'Toole A, Nwanne O, Tomlinson T. Inflammatory Bowel Disease Increases Risk of Adverse Pregnancy Outcomes: A Meta-Analysis. Dig Dis Sci 2015; 60: 2750-2761

[19] Bortoli A, Pedersen N, Duricova D et al. Pregnancy outvome in inflammatory bowel disease: prospective European case-control ECCO EpiCom study, 2003-3006. Aliment Pharmacol Ther 2011; 34: 724-734

[20] Tandon P, Govardhanam V, Leung K et al. Systematic review with metaanalysis: risk of adverse pregnancy-related outcomes in inflammatory bowel disease. Aliment Pharmacol Ther 2020; 51: 320-333. doi:10.1111/apt.15587

[21] Burke KE, Haviland M], Hacker MR et al. Indications for mode of delivery in pregnant women with inflammatory bowel disease. Inflamm Bowel Dis 2017; 23: 721-726

[22] Schmidt M. Betreuung von Frauen mit chronisch entzündlichen Darmerkrankungen (CED) - Was muß ich in der Schwangerschaft und bei der Geburt beachten? Gyn Praxis 2019; 45: 417-424

[23] Hatch Q, Champagne B], Maykel JA et al. Crohn's disease and pregnancy: the impact of perianal disease on delivery methods and complications. Dis Colon Rectum 2014; 57: 174-178

[24] Foulon A, Dupas JL, Sabbagh C et al. Defining the Most Appropriate Delivery Mode in Women with Inflammatory Bowel Disease: A Systematic Review. Inflamm Bowel Dis 2017; 23: 712-720

[25] Jiang H, Qian X, Carroli G et al. Selective versus routine use of episiotomy for vaginal birth. Cochrane Database Syst Rev 2017; (2): CD000081

[26] Remzi FH, Gorgun E, Bast J et al. Vaginal delivery after ileal pouch-anal anastomosis: a word of caution. Dis Colon Rectum 2005; 48: 1691-1699

[27] Julsgaard M, Norgaard M, Hvas CL et al. Self-reported adherence to medical treatment, breastfeeding behaviour, and disease activity during the postpartum period in women with Crohn's disease. Scand J Gastroenterol 2014; 49: 958-966

[28] Mahadevan U, McConnell RA, Chambers CD. Drug Safety and Risk of Adverse Outcomes for Pregnant Patients With Inflammatory Bowel Disease. Gastroenterology 2017; 152: 451-462.e2 